Chapter 3

\title{
From Wholesale Energy Markets to Local Flexibility Markets: Structure, Models and Operation
}

Fernando Lopes ${ }^{*, 1}$

* LNEG - National Laboratory of Energy and Geology, Est. Paço do Lumiar 22, Lisboa, Portugal

\section{ABSTRACT}

Most energy markets (EMs) across Europe are based on a design framework involving day-ahead, intra-day and bilateral markets, operating together with balancing markets. This framework was set out, however, when the vast majority of generation units were controllable and fuel-based. The increasing levels of renewable generation create unique challenges in the operation of EMs. In this context, flexibility markets are starting to be recognized as a promising and powerful tool to adequately valorise demand-side flexibility. This chapter describes the models underlying both centralized and bilateral markets, analyses the operation of several European markets, introduces some energy management tools, analyses the pressing issue of flexibility in system operation, and describes various pioneering flexibility platforms.

\section{KEYWORDS}

Energy markets, Market architecture, Market models and operation, Renewable energy, Clean energy transition, Flexibility in system operation, Flexibility markets, Agent-based tools for energy markets.

\subsection{INTRODUCTION}

Energy markets (EMs) are built on well-established principles of competition and transparency, representing a good way to guarantee affordable energy prices and secure energy supplies. To a large extent, European markets have adopted a common framework based on general design principles and common rules for the internal market of electricity [1, 2]. These rules have subsequently been complemented by legislation concerning electricity trade and grid operation aspects, as well as measures against market abuses [3, 4]. These include rules on the separation of energy supply and generation from the operation of transmission networks (unbundling), the independence of national energy regulators, and fair retail markets. They also guarantee that energy consumers enjoy high standards of consumer protection.

1 Corresponding Author. Email: fernando.lopes@Ineg.pt 
The 'common design framework' involves a day-ahead market (DAM) and an intra-day-market (IDM), operating together with a bilateral market, and complemented with balancing markets (see, e.g., $[5,6])$. In short, market participants submit hourly bids to the DAM until a particular hour of day $d$ before the day of operation $(d+1)$. Market-clearing prices and equilibrium quantities are calculated using EUPHEMIA (acronym for European Union Pan-european Hybrid Electricity Market Integration Algorithm) [7]. The intraday market may involve several sessions similar to the DAM daily auction, and can be cleared several times once the DAM has been cleared. ${ }^{2}$ Also, the IDM may operate continuously seven days a week, all year around. The bilateral market provides a hedge against the price volatility of centralized trading. Finally, balancing markets are in place to set prices and schedules to match the imbalances caused by the variability and uncertainty of power systems.

This 'common design framework' was set out, however, when the vast majority of generation units were controllable and fuel-based, meaning that production could be shifted in time with limited economic impact. This is no longer true, since a significant part of the traded power comes from renewable energy sources. The unique characteristics of renewable generation-more variable, less predictable and decentralized than traditional generation-influence the performance and outcomes of power markets [8]. In particular, large penetrations of renewables reduce market-clearing prices due to their low-bid costs. Also, high levels of renewable generation increase market price volatility because of their increased variability.

Noticeably, the increasing levels of renewable generation create unique challenges in the design and operation of power markets [8]. Chief among these is the need to incentivize increasing levels of flexibility in a cost-effective way to manage the rising variability and uncertainty of the net load (i.e., load minus renewable generation) [9]. Also important, is the need to ensure revenue sufficiency for achieving long-term reliability [10]. Thus, there is a growing need to adapt current market rules to the new market realities.

In 2019, EU published new rules for the internal market for electricity [11, 12]. For wholesale markets, the new rules focus on short term markets to improve competition and liquidity, dispatch rules adapted to the new market reality, scarcity pricing without price caps, and a remuneration for evolving technologies, such as demand response and energy storage, more in line with the flexibility provided by such services. For retail markets, the new rules empower consumers and communities to actively participate in the market, by generating electricity, consuming it or selling it back to the market, and mainly by offering demand response, energy storage, and specific flexibility products, receiving remuneration directly or through aggregators.

\footnotetext{
2 In terms of structure, North American markets are similar to European power markets, although they typically include a day-ahead market and a short term market, referred to as real-time market (RTM), to set prices and schedules for 5-minute intervals [13].
} 
Several improvements and extensions to the 'common design framework' have also been proposed during the past few years, such as extended marginal pricing based on the convex-hull approach, explicit products for flexible ramping provision [14], and pay-for-performance regulation (but see [8] for an in-depth discussion). At present, however, it is unclear whether or not such improvements are adequate to incentivize the levels of flexibility required by the rising penetrations of renewables.

In this context, flexibility markets are starting to be recognized as a promising and powerful tool to adequately valorize demand-side flexibility (see, e.g., [15]). There are some ongoing pioneer projects related to flexibility marketplaces with small-scale research demonstrators, such as OSMOSE [16] and WindNODE [17]. Also, a few initiatives are in a piloting phase, notably NODES [18], Enera [19], Piclo Flex [20] and GOPACS [21].

The remainder of the chapter is structured as follows. Section 3.2 describes the centralized and bilateral models underlying most European markets. Section 3.3 analyses the operation of four central European markets, namely Nord Pool (the Nordic and Baltic market), EPEX Spot (the market for Central Western Europe), MIBEL (the Iberian market), and GME (the Italian market). Following this material, Section 3.4 describes some energy management tools to simulate the operation of power markets. Section 3.5 analyses the pressing issue of flexibility in system operation and Section 3.6 describes four key flexibility European markets, specifically NODES, Enera, Piclo Fex and IREMEL. Finally, Section 3.7 presents some concluding remarks.

\subsection{WHOLESALE MARKETS: MODELS AND OPERATION}

European power markets evolved in similar directions, following standard design principles. As noted, the 'common design framework' involves four different types of markets: day-ahead and intra-day markets, operating together with bilateral markets, and complemented with balancing markets. ${ }^{3}$ Fig. 3.1 depicts schematically the various markets.

Day-ahead Market. This market is the central market for trading energy in advance of time when the energy is produced and consumed, and is executed every day. For a particular day of operation $d$, the DAM clears typically at 12 noon of day $(d-1) \cdot{ }^{4}$ The pricing method is founded on the marginal pricing theory, where the price equals the short-run marginal cost [23]. Pricing plays an important role in the DAM, as it sends monetary signals to all market entities, signals that influence their participation in the market.

\footnotetext{
3 Notation is somewhat abused here, since day-ahead, intra-day, bilateral and balancing markets are indeed submarkets of power markets [22]. However, submarkets are themselves markets, and thus they will be referred to simply as markets throughout the chapter.

4 Trading in the day-ahead market is typically done on an hourly basis, although time intervals could be reduced to 15 minutes in the coming years [11].
} 


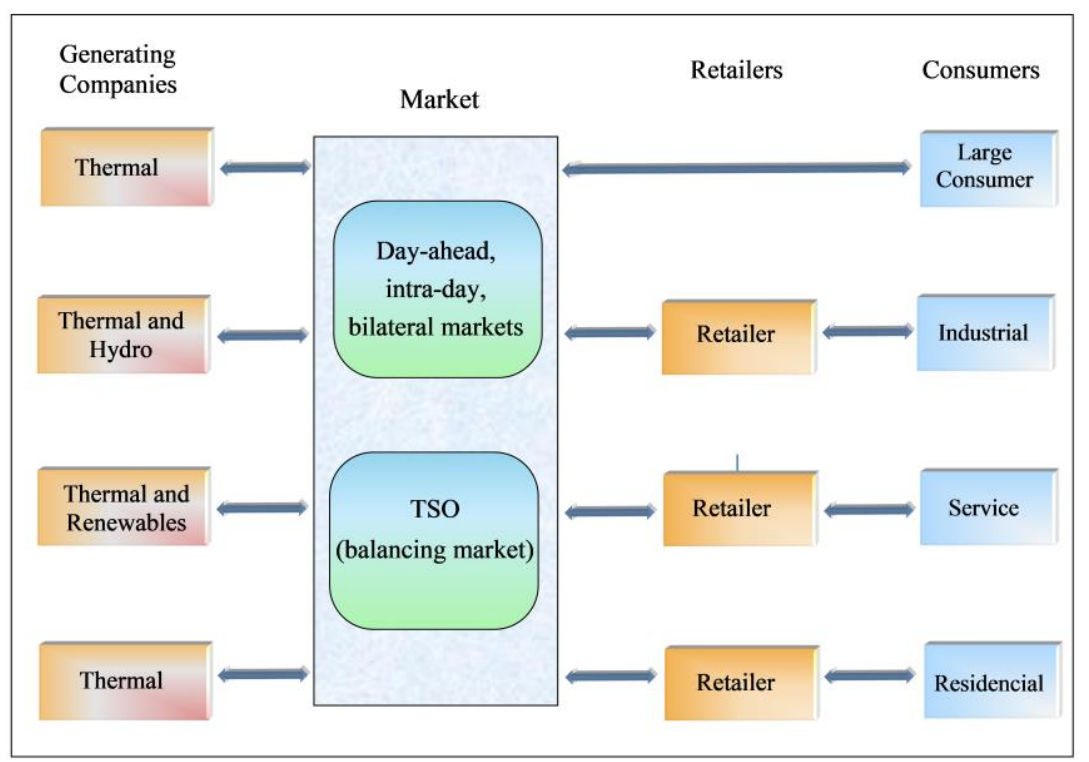

FIGURE 3.1 Typical energy markets and key market players

Under system marginal pricing (SMP), generators compete to supply demand by submitting bids to the market, which typically involve a price and an energy quantity for every hour of the day of operation. In a more general form, bids to sell energy may include start-up costs, as well as operating constraints and the availability of generators. A market operator collects the bids and sorts them according to the price, leading to a supply curve. Buyers submit load purchase offers for every hour of the day under consideration. These offers are also collected by a market operator, who ranks them in order of decreasing price, building a demand curve. The market-clearing price is defined by the intersection of the supply curve with the demand curve. This price is applied to all generators uniformly, regardless of their bids or location. The equilibrium quantity is determined as the sum of all offers that are satisfied at the marketclearing price [6, 22].

Under locational marginal pricing (LMP), a more complex variation of system marginal pricing, the market operator runs an optimal power flow (OPF) procedure that defines the energy prices at different locations in the system. Thus, LMP involves the pricing of electrical energy according to the location of its injection or withdrawal from the transmission grid. As in SMP, generators submit bids to sell energy and buyers load purchase offers. The main difference now is an optimization process that is subject to various system constraints, such as voltage limits. This optimization may be based on a full AC OPF, although a linearized OPF is sometimes considered, to simplify the numerical complexity. Simplified OPF models can result, however, in inefficiencies and cross-subsidies among competing agents. 
In the past, European power exchanges (PXs) used different market algorithms, such as COSMOS, SESAM, SIOM and UPPO, which focused on local features and products, and were typically not able to cover global requirements. This leads to the Price Coupling of Regions (PCR) project, an initiative of eight European PXs, who developed a single price coupling algorithm, commonly known as EUPHEMIA. Since 2014, this algorithm is progressively used to calculate energy prices and quantities in different regions across Europe, maximizing the global welfare and increasing the transparency of the computation of prices and flows [7].

Intra-day Market. This market sets prices and schedules some periods ahead to facilitate balancing on advance of real time. Specifically, the intra-day market is mainly used for: (i) adjusting energy quantities based on the results of the day-ahead market, (ii) managing forecast errors or unforeseen events, (iii) adjusting from hourly positions to 30 minutes or even 15 minutes, and (iv) offering flexible generation as a substitution for renewables. The traditional trading procedure is based on one or more daily auctions. Recently, a continuous trading procedure has also been adopted in various markets around the world.

In case of daily auctions, the generic trading procedure is essentially identical to that of the day-ahead market and details are omitted. For day $d$, the intraday market may be cleared one or more times once the DAM has been cleared. Auctions may differ according to the time period under consideration. Specifically, trading may be based on a 60-min auction, 30-min auction, or 15min auction, thus providing different re-balancing possibilities for market participants. Each auction aims at optimising the global welfare. The price determined by the market is the price at which all trades will be executed.

Continuous intra-day markets run seven days a week, all year around. Market participants submit bids to sell energy and load purchase offers to the order book of a trading platform (such bids and offers are often referred to as orders). A trading session is a time period during which orders are matched automatically. Unexecuted orders remain in the order book until their expiry or are cancelled. The order matching rules ensure that orders are executed at the best price available in the system. Typical contracts for the next day include hourly contracts, 30-min contracts and 5-min contracts. The lead time - that is, the time between the end of the trading session and the start of the delivery period - may range from 60 minutes to 5 minutes.

Generally speaking, the continuous trading matching algorithm, commonly known as SIDC (single intra-day coupling) algorithm, involves two key modules: the shared order book (SOB) module and the capacity management module (CMM). The former contains the basic functionality for continuous trading, like order entry, order management and order matching. The latter provides the functionality for managing and allocating available transmission capacity between all areas in the underlying network [24]. 
Now, the performance of centralized trading based on auctions for both DAM and IDM is often affected by several important factors, notably price volatility [5]. Also, centralized trading involves basically ex-post energy prices, known only after the definition of the dispatch. ${ }^{5}$ Accordingly, to hedge against price uncertainty, generators and loads may choose to enter into bilateral trading.

Bilateral Markets. A bilateral market is a market in which private parties, sellers and buyers, negotiate bilateral agreements for the exchange of electricity under mutually acceptable terms. Such market provides both standardized financial and physical contracts that span from days to years, notably forwards, futures, options and swaps [6,22]. Each contract has its own price that depends only on the arrangements between the interested parties. This makes bilateral agreements falling under the category of the payas-bid pricing scheme, since the parties are paid according to their offers, rather than on the system marginal price or the marginal nodal price. Also, bilateral trades involves basically ex-ante prices, known at the end of the negotiation process.

Market participants enter into bilateral contracts by submitting orders directly to the order book of a trading platform. For each order, several elements should be specified, including the nature (buy or sell), the type of contract, the price, the energy quantity (expressed in a full number of contracts), and the validity period. Trading may take two forms: continuous or auction. In continuous trading, buy and sell orders for each contract likely to interfere with each other generate transactions. This means that the trading platform checks continuously for matching buy and sell orders. When a match is found, the orders for the corresponding contract generate a transaction-that is, a trade executed on the contract-and give rise to a particular market price. Thus, in a given trading session, a number of market prices can be generated.

Auction trading involves a pre-defined call period during which orders can be introduced in the order book. This period may be of open or closed type. The former involves the display of a provisional equilibrium price corresponding to the situation that results from the submitted orders at any moment. The latter involves no display of information. The call period is followed by the determination of an equilibrium price based on the aggregated values of the buy and sell orders. This means that auction trading involves the generation of a market price only. The orders at a price equal or higher than the equilibrium price generate transactions up to a maximum executable volume. This volume corresponds normally to the total of buy orders at a price equal or higher than the equilibrium price (or, if lower, to the total of sell orders at a price equal or lower than the equilibrium price). Typically, orders are executed according to specific criteria (e.g., a buy order at the highest price and a sell order at the lowest price benefit from priority for execution).

5 The dispatch consist essentially in a set of market instructions, especially with respect to defining the generators that provide power at any point in time and their output levels [5]. 
As noted earlier, a generally accepted strategy for market players to hedge against the price uncertainty of centralized trading is to engage in bilateral contracts that offer more stable rates over time. The drawback, however, is that a fixed bilateral price could be lower than the DAM price, a situation that is disadvantageous to sellers and advantageous to buyers. Alternatively, if the bilateral price is higher than the DAM price, an opposite situation will take place. Thus, there is normally a usual linkage between central and bilateral markets $[5,22]$. Although these two markets are quite different, the centralized market price is typically the leading price indicator for bilateral trades.

Balancing Markets. In addition to all the aforementioned markets - that is, day-ahead, intra-day and bilateral markets — balancing markets represent the major tool for correcting the imbalances relative to the physical trade of energy, in order to maintain equality between production and consumption, and also to ensure power grid stability. Balancing markets are operated by transmission system operators (TSOs), who are usually neutral and noncommercial organizations. They make use of balancing products - such as, primary reserve, secondary reserve or automatic frequency restoration reserve (aFRR), and tertiary reserve or manual frequency restoration reserve (mFRR) - to ensure the maintenance of the system frequency around a nominal value $(50 \mathrm{~Hz}$ [25]).

Market entities include balancing service providers (BSPs), who are able to provide balancing services to TSOs, as well as balancing responsible parties (BRPs), who are financially responsible for their imbalances. BSPs should qualify for providing bids. BRPs handle balance responsibility to TSOs for production plants, consumption (including grid losses), and physical electricity trading. They should strive to be balanced in real time or help the power system to be balanced [26].

The prices for energy and (some) balancing products are calculated in a similar manner, taking in account the marginal pricing concept (typically, payas-cleared). TSOs are responsible for procuring balancing services and thus, they constitute the demand side. BRPs may update their schedules until the balancing energy gate closure time, which should be as close as possible to real time. BSPs may submit and update balancing power bids from balancing products until the gate closure time of the procurement process. Thus, BSPs with available generation capacity (e.g., producers) may submit up-regulation bids to the TSO. Likewise, BSPs able to reduce consumption may submit down-regulation bids to the TSO. In case the TSO is procuring up-regulation, the up-regulation orders with lowest prices are activated until the procured quantity is reached. The price of the last up regulated MW sets the upregulation price. A similar procedure is used to find the down-regulation price. There is typically a linkage between the balancing market and the day-ahead market (and the IDM as well). Pricing for balancing energy takes normally into account the pricing method in the day-ahead and intraday timeframes. 


\subsection{KEY EUROPEAN MARKETS}

This section describes four key European markets, namely Nord Pool, EPEX Spot, MIBEL and GME.

The Nordic and Baltic power market (Nord Pool). This market operates a day-ahead market (Elspot) and an intra-day market (Elbas). Elspot accepts several different types of orders according to the trading region, including single hourly orders, block orders, flexible orders and exclusive groups. Market participants can consider any type of orders or a combination of different types to meet their interests. The Nordic and Baltic areas are divided into bidding areas to handle congestions in the electricity grid. The market closes at 12:00 CET and producers are paid according to their area price. Similarly, all buyers pay the same area price [27, 28].

Elbas supplements the day-ahead market and offers 15 minute, 30 minute, hourly and block products, providing significant flexibility to meet the needs of different market areas. Order types include limit orders, user-defined block orders, pre-defined orders, and iceberg orders. Trading is essentially continuous, although one or more daily auctions may be conducted by Nord Pool, from time to time. In continuous trading, transactions are matched automatically when concurring orders are registered in the trading platform. Prices are set based on a first-come, first-served principle, where best prices come first-that is, the highest buy price and the lowest sell price. Orders with the same price limit are prioritized by their time stamp oldest first. Trading takes place every day around the clock, 365 days a year, until one hour before delivery $[27,29] .{ }^{6}$

Elspot and Elbas are complemented by a financial market and local balancing markets. The former is operated by NASDAQ OMX and manages the risks inherent to the two central markets (i.e., Elspot and Elbas). Contracts can be made for up to six years and typically consider the Elspot system price as the reference price. The latter are operated by the respective TSOs (e.g., Energinet [29], Svenska kraftnät [30] and Statnett [31]). They are mainly used for making final adjustments and ensuring the correct frequency in the grid and the security of supply. To this end, TSOs buy/sell power from/to market participants in the delivery hour on the basis of bids for upward and downward regulation. Specifically, players submit bids for specific prices (€/MWh) and volumes (MW) over specified periods of time. Bids refer to the next day of operation $(d)$ and may or may not cover the entire day. The prices and volumes should be specified-hour by hour-separately for upward and downward regulation. Bids are submitted during day $d-1$ (e. g, until 17:00h) and the entered prices and volumes can be adjusted up to 45 minutes prior to the upcoming delivery hour [30-35].

${ }^{6}$ Strictly speaking, trading may take place until either one hour before delivery, or 30 minutes or even 5 minutes before delivery, depending on the trading region [26]. 
The market price is determined according to the marginal price principle and calculated on an hourly basis. It is set at the price of the most recently activated bid provided that bottlenecks or other problems do not hinder the free exchange of power between different market areas. Players must be able to fully activate a given bid in a specific period of time from receipt of the activation order (typically, in a maximum of 15 minutes) [30-35].

The Market for Central Western Europe (EPEX SPOT). This market operates organized day-ahead and intra-day markets for twelve European countries of the Multi-Regional Coupling area (apart from Switzerland). ${ }^{7}$ The DAM considers two daily auctions: an hourly auction and an half-hourly auction in Great Britain (GB). The order book for the hourly auction opens 45 days in advance and closes one day before delivery at 12:00 CET (11:00 for Switzerland). Tradable products include 24 hourly contracts corresponding to the 24 delivery hours of the following day $(d)$. Prices must be included between a minimum and a maximum value for each market area, typically -500 and $3000 € / \mathrm{MWh}$, respectively. Following the hourly auction, the half-hourly auction in GB provides market participants with the opportunity to balance physical portfolios to the half-hour delivery. Tradable products include 30minute contracts with delivery on the following day. The order book closes at 15:30 (GMT) of day $d-1$ and market results are published from 15:45 onwards [36-38].

The intra-day market offers both continuous and auction trading in twelve European countries. Continuous trading takes place 24 hours a day, all year around. Tradable products for the next day include 1-hour contracts, 30minute contracts and 15-minute contracts. The order book opens in day $d-1$, at 00:00 (GMT) in GB, 14:00 (CET) in the Nordics, and 15:00 (CET) in central Europe. Trades are executed as soon as two orders entered into the M7 platform match automatically. The lead time is 30 minutes for France, 15 minutes for GB (for 30-minute contracts), and 5 minutes for Austria, Belgium, Germany, the Netherlands, and Switzerland. The IDM considers various daily auctions, namely a 15-minute auction in Germany, two 30-minute auctions in GB (one at 17:30 of $d-1$ and another at 8:00 of $d$ ), and two 60-minute auctions in Switzerland (at 16:30 of $d-1$ and 11:15 of $d$, respectively). The 15-min auction was introduced in 2014 and counts for $13 \%$ of the intra-day traded volumes. The two GB auctions are coupled with Ireland and the traded volume represent $20 \%$ of the total intra-day volume in GB. The Swiss auctions are the latest addition (April 2019) and were created to provide new rebalancing opportunities for market participants. They are coupled with Italy and allow players to benefit from the pooling of liquidity built from the existing Italian M12 and M16 auctions [36-38].

7 Strictly speaking, EPEX SPOT operates a day-ahead market, an intra-day market, a local flexibility market and an organized market for French capacity guarantees. Also, EPEX SPOT offers physical fulfilment services in partnership with EEX [36]. Section 3.6 presents a detailed description of the flexibility market. 
The DAM and the IDM are complemented by a power derivatives market (EEX) and different balancing markets operated separately by the system operators of the respective countries (e.g., RTE [39], 50Hertz [40] and Tennet [41]). For instance, RTE (Réseau de Transport d'Électricité), the French transmission system operator, maintains a balancing mechanism to ensure the security of the power system at all times. Balance responsible entities may submit, modify or withdraw offers for day $d$ at one of the gate closures: 4 p.m., 10 p.m. and 11 p.m. of day $d-1$. Offers involve essentially the following: a balancing direction (upward/downward), a time-period, a price that may vary according to six time slots (e.g., 12:00-6:00 a.m. or 2:00-5:00 p.m.), and usage conditions. RTE selects the offers that correspond to the real-time balancing requirements, based on economic precedence and conditions for use. Offers are remunerated by considering the pay-as-bid pricing scheme. For each half-hour period, the balancing mechanism gives a reference price applicable for settling the imbalances, based on the average weighted prices of upward and downward balancing offers or the EPEX SPOT price [39, 42].

The Iberian Market (MIBEL). The day-ahead market sets scheduling quantities and energy prices at 12 noon of day $d-1$, for the 24-hours of day $d$. Market players may trade energy regardless of whether they are in Portugal or Spain. Sale bids may be simple or incorporate complex conditions in terms of their content, including indivisibility, load gradients, minimum income and scheduled stop. Purchase bids are typically simple bids, indicating a price and an amount of power. Sale and purchase bids are accepted according to their merit order, until the interconnection between Portugal and Spain is fully occupied. In case the capacity of the interconnection permits the flow of the energy traded in a certain hour of day $d$, the price for that hour will be the same for both countries. Otherwise, if the interconnection is fully occupied, the price-setting algorithm (EUPHEMIA) will be run separately for the two countries and there will be a different price of electricity for Portugal and Spain. The underlying mechanism is referred to as market splitting and is commonly used in Europe [43, 44].

The intra-day market runs after the daily market and involves six trading sessions based on auctions, similar to the DAM auction, where hourly prices and energy quantities are determined by the points where the supply and demand meet. The first session opens at 14:00 and closes at 15:00 of day $d$ 1 , involving a schedule horizon of 24 hours. The last session opens at 9:00 of day $d$ and closes at 9:50 of the same day, involving a schedule horizon of 12 hours. Thus, this market permits to readjust previous commitments (for purchasing and selling energy) up to four hours to real time. Sale and purchase bids may be simple or incorporate complex conditions, according to their content. This means that the market operator may run a conditioned matching method considering specific conditions (e.g., indivisibility and load gradient) $[43,44]$. 
The intra-day market also operates continuously. Market participants have the possibility to better manage their imbalances by gaining access to market liquidity at the national level and also benefiting from the liquidity available in markets in other areas of Europe. The purchase and sale bids introduced by players in one country may be matched by orders submitted in a similar manner by players in other European countries. The opening of the negotiation for all contracts for the next day $d$, in the price areas of Portugal and Spain, is made after the end of the first auction of day $d-1$, provided the system operator has published the definitive daily-ahead schedule for day $d$. Matched orders give rise to firm transactions (i.e., sale orders imply a delivery obligation and purchase orders a purchase obligation) [43, 45].

The day-ahead and intra-day markets are complemented by a financial market operated by OMIP (The Portuguese Electricity Market Operator) [46]. Also, the DAM and IDM are complemented by balancing markets in Portugal and Spain, operated by REN [47] and REE [48], respectively. For instance, in Portugal, the primary regulation ancillary services are mandatory and the system operator notifies market players every year about the minimum load variation percentage together with the maximum response speed in the event of different frequency deviations. To assign secondary regulation energy band ancillary services, the system operator publishes the hourly requirements for the next day together with the provisional daily viable schedule. This is followed by a period of bid reception and price definition. The submission of offers opens at 7:00 p.m. and closes and 7:45 p.m. of day $d-1$. For the assignation of the tertiary regulation ancillary services, market agents should send their hourly bids for maximum production level changes until 8:00 p.m. of day $d-1$. The offers may be adjusted up to 20 minutes after the publication of the final hourly program (PHF) of the different intra-day sessions [49].

The Italian Electricity Market (GME). The day-ahead market (MGP) hosts most of the electricity trades and the intra-day market (MI) allows market participants to modify the schedules defined in the MGP by submitting additional bids in different sessions. More specifically, MGP trades hourly energy blocks for the next day $d$. This market opens at 8 a.m. of the ninth day before the day of delivery and closes at 12 p.m. of the day before the day of delivery $(d-1)$. The intra-day market takes place in seven sessions (Ml1 to MI7). The sessions are organized in the form of implicit auctions of electricity, in sequence, and with different closing times. For instance, MI1 opens at 12.55 p.m. of day $d-1$ and closes at 3 p.m. of the same day. And MI7 opens at 5:30 p.m. of $d-1$ and closes at 3:45 p.m. of day $d[50,51]$.

MGP and MI operate together with a daily products market (MPEG), where players can trade both base and peak energy products with the obligation of delivery. This market operates continuously on weekdays. The sessions take place from 8.00 to 17.00 of day $d-2$, and also from 8.00 to 9.00 of day $d-1$. The products to be delivered on Saturday, Sunday and Monday are traded on the corresponding Friday [50]. 
MGP, MI and MPEG are complemented by a forward electricity market (MTE) and an ancillary services market (MSD). The latter is operated by the Italian system operator (Terna [52]) and involves a scheduling sub-stage (ex-ante MSD) and a balancing market (MB). Both markets include multiple sessions. For instance, MB takes place in six sessions: MB1 to MB6. The first session takes into consideration the valid bids and offers that players submitted in the previous ex-ante MSD session. For the other five sessions, the submission process opens at 10.30 p.m. of day $d-1$, and closes 1 hour and a half before the first hour which may be negotiated in each session. The MB is mainly used to provide the service of secondary control and to balance energy injections and withdrawals into/from the grid in real-time $[50,51]$.

\subsection{AGENT-BASED TOOLS FOR ENERGY MARKETS}

Traditional market models include optimization and equilibrium models (see [53] for a review). Most optimization models focus on a profit maximization problem in which a centralized decision-maker pursues the maximum profit. These models typically consider a single objective function subject to a set of technical and economic requirements (see, e.g., [54]). Equilibrium models represent the global market behaviour and take into consideration competition among market participants. They are often formulated as a simultaneous profit maximization program that considers the different players competing in the market. Also, they are based on the Cournot competition concept or the supply function equilibrium approach (see, e.g., [55, 56]).

Both optimization and equilibrium models continue to provide very useful insights into the operation of power markets, but present to a large extent limitations in their ability to adequately analyse existing market forces and the dynamics that characterize actual markets. Indeed, traditional models were developed under the implicit assumption of a centralized decision-making process and are often considered a poor fit to liberalized energy markets, where operation decisions are decentralized and strategically taken by different market operators. Also, equilibrium models consider algebraic and/or differential equations that impose limitations on the representation of competition and are typically very hard to solve. And the fact that power systems are based on the operation of generation units with complex constraints only contributes to complicate the situation [53].

The distributed nature and complexity of power markets calls, therefore, for richer and more flexible modelling techniques [57]. Multi-agent systems (MAS) are essentially systems composed of multiple computing elements, known as software agents, that interact to solve problems that are beyond the individual capabilities or knowledge of each agent. Such elements are also typically able to perform flexible autonomous actions and capable of managing cooperative and competitive interactions with other agents, by making use of methods and techniques from Artificial Intelligence [58, 59]. 
The multi-agent approach presents itself as a promising approach to accurately model and study in detail the behaviour of power markets over time. Accordingly, it has attracted considerable attention over the last years and a number of energy management tools have emerged, including SEPIA [60], EMCAS [61], NEMSIM [62], AMES [63], PowerACE [64], MASCEM [65], GAPEX [66], and MATREM [67, 68]. Also, the work presented in [69] considers software agents to put together real-time simulation and laboratory emulation of resources, focusing deeply on modelling electric power system components for realistic simulation of micro-grids and local energy markets.

MATREM (acronym for Multi-Agent TRading in Electricity Markets) is an agent-based simulation tool developed at LNEG (by the author and his group) to help manage both the complexity of wholesale markets and the unique challenges of bilateral contracting in retail markets. The tool operationalizes a power exchange (comprising a day-ahead market and an intra-day-market), a derivatives exchange (comprising a futures market), a marketplace for negotiating tailored (or customized) long-term bilateral contracts, and a balancing market. Also, MATREM supports various types of market entities, notably generating companies (e.g., wind, solar, hydro and thermal producers), retailers, large and small consumers, aggregators of consumers, virtual power producers (e.g., aggregators of wind producers), market operators and system operators. These entities are modelled as software agents able to interact with other agents to meet their design objectives.

Two main types of software agents are being considered: market agents and assistant agents. Market agents represent the entities that take part in the different simulated markets. Assistant agents are further categorized into interface managers and intelligent assistants. The former are responsible for managing the interfaces of the various markets. The latter provide support to the user in making strategic decisions. The agents are being developed using the JAVA programming language and the JADE framework [70]. A classification of MATREM according to various dimensions associated with both electricity markets and intelligent agents can be found in [67]. Also, a detailed description of the various markets and entities supported by the tool is presented in [68]. Fig. 3.2 presents a snapshot of the tool and the remainder of this section gives an overview of the simulated markets.

MATREM: Overview of the Simulated Markets. MATREM is an agentbased simulation tool for analysing the behaviour and outcomes of power markets, including markets with increasing levels of renewable generation. The day-ahead market (DAM) is a central market where generation and demand can be traded on an hourly basis. To this end, a market operator agent collects all bids for a given hour $h$ and sorts them according to the price. In a next step, aggregated supply and demand curves are determined. Supply and demand are then matched by adding up all volumes. The market-clearing price is determined by the last unit necessary to satisfy the demand (see, e.g., $[71,72])$. 


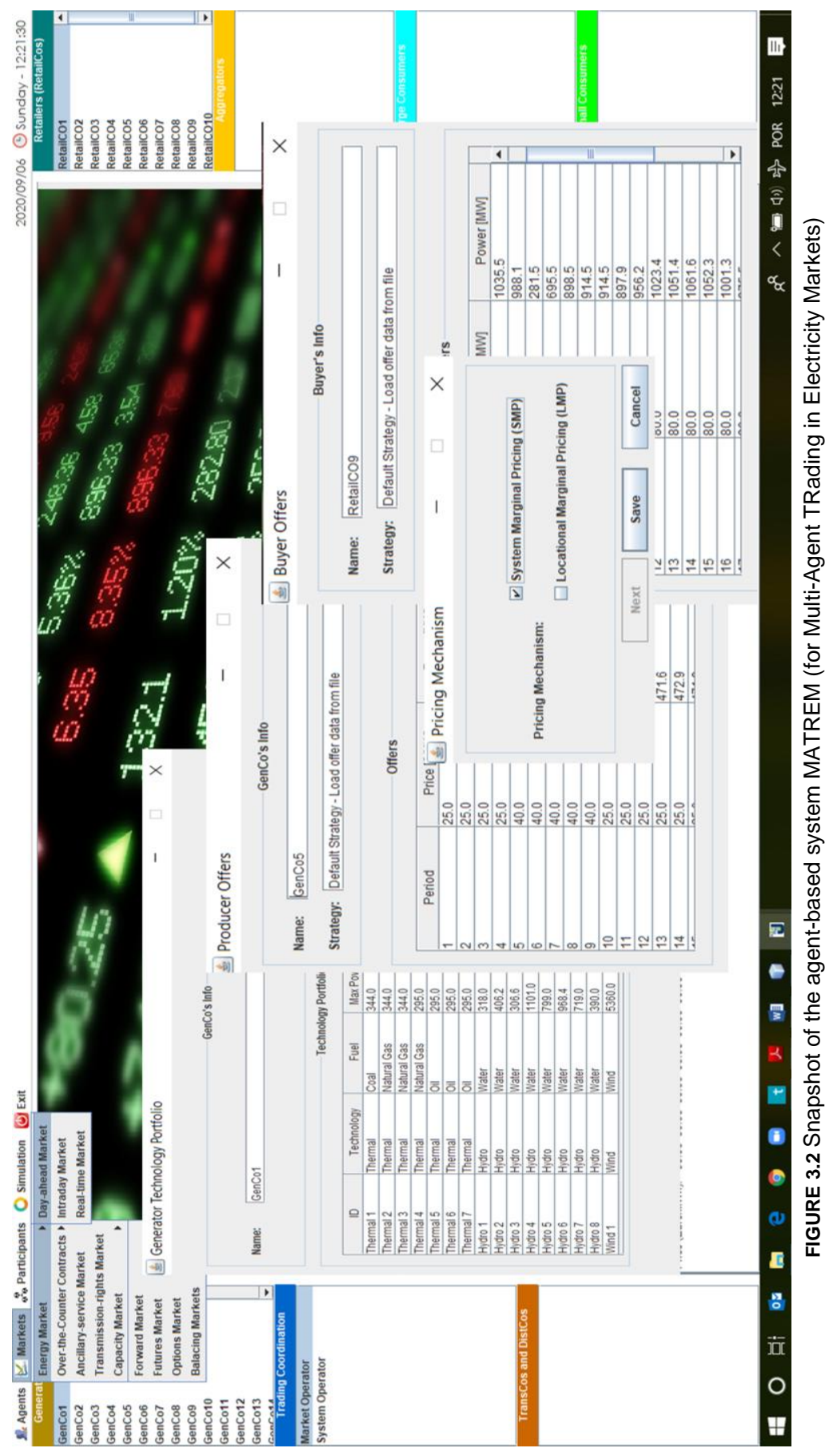


The intra-day market is a short-term market and involves several auction sessions. It is used to make adjustments in the positions of participants as delivery time approaches (such as managing forecast errors related to renewable generation and unforeseen events). Both the DAM and the IDM are based on the marginal pricing theory. Two pricing mechanisms are supported: system marginal pricing and locational marginal pricing.

The futures market is an organized market for both financial and physical products conditioned on delivery at a specific time and place. Such products may span from days to years and typically hedge against the financial risk (i.e., price volatility) inherent to day-ahead and intra-day markets. Players enter orders involving either bids to sell or buy energy in an electronic trading platform that supports anonymous operation. The platform automatically and continuously matches the bids likely to interfere with each other.

The balancing market is a market for primary reserve (or frequency control reserve), secondary reserve (or fast active disturbance reserve), and tertiary reserve (or slow active disturbance reserve), for the provision of system services. For the particular case of tertiary reserve, a system operator agent defines the needs of the power system, collects the bids from the market participants, and determines the market prices by considering a simplified version of the system marginal pricing algorithm (see, e.g., [73]).

Especially noteworthy is the possibility to negotiate the details of two different types of tailored (or customized) long-term bilateral contracts, namely forward contracts (see, e.g., [74]) and contracts for difference (see, e.g., [75]). Such contracts cover the delivery of large amounts of energy over longs period of time (several months to years). Their terms and conditions are very flexible and can be negotiated privately to meet the objectives of two parties. To this end, market agents are equipped with an interaction model that handles twoparty and multi-issue negotiation (see, e.g., [76-78]). The negotiation process involves and iterative exchange of proposals and counter-proposals. A proposal (or offer) is a set of issue-value pairs, such as 'energy price $=50$ $€ / \mathrm{MWh}$ ', 'contract duration = 12 months', and so on. A counter-proposal is a proposal made in response to a previous proposal. Negotiation strategies and tactics are functions that define new values for each issue at stake throughout negotiation. The final result may be either agreement or no agreement. This design feature of the agent-based simulation tool represents, we believe, a new and powerful feature of MATREM.

Overall, the current version of MATREM allows to conduct different studies on market design and operation (see [79] for a study to investigate the merit order effect of the deployment of wind power in Portugal, and [80] for another study to analyse the impact of demand response on the lberian electricity market price). Also, MATREM was recently updated with new market products [81]. Furthermore, the author (and his group) is conducting a study at LNEG to investigate the use of local flexibility markets and to extend the system with a new flexibility market. 


\subsection{THE ENERGY TRANSITION AND FLEXIBILITY MARKETS}

The energy sector is experiencing a rapid and profound change largely driven by the rising levels of renewable generation, the increasing deployment of decentralized resources, and the so-called Internet of Things (IOT):

- Renewable generation has grown significantly during the past decade, surpassing all expectations, and this growth is expected to continue during the coming years (see, e.g., $[8,79]$ ).

- Traditional (fossil-fuelled) resources connected to the transmission grid are increasingly being phased-out and, at the same time, non-traditional resources connected to the distribution grid, such as wind and solar power plants, are increasingly being part of the supply mix (see, e.g., $[8,79]$ ).

- Micro-grids - that is, groups of interconnected loads and decentralized resources within clearly defined electrical boundaries that act as single controllable entities with respect to the grid-are being increasingly implemented in power systems (see, e.g., [82]).

- End users are increasingly transforming from passive consumers into prosumers, who want to actively participate in the energy market, either individually or through aggregation services (see, e.g., [83].

- Energy conversion technologies, such as power-to-gas units and fuel cells, are starting to become market-ready; also, the market introduction of electric vehicles (EVs) is starting to become economically viable (see, e.g., $[82,83])$.

- The society is generally becoming more digitalized, giving rise to an Internet of Things, and thus making possible the exchange of information between any device and entity in the power system (see, e.g., [83-85]).

Put simply, three mega-trends, commonly referred to as the "three-D's"Decarbonisation, Decentralization and Digitalization — are shaping the energy landscape.

Clearly, the rapid expansion of renewables is challenging power systems in terms of flexibility for short-term operation [9]. Renewable generation adds variability and uncertainty to power systems at multiple timescales. And besides variability and uncertainty, renewable generation is nonsynchronous to the electrical frequency and location constrained, meaning that may be located far from load centers.

The rise of renewables is also being accompanied by a growing demand for electrical energy, mainly driven by the electrification of large parts of the residential sector, as well as the electrification of the transport sector (notably, the trend towards electric vehicles). The electrification of these sectors can significantly influence the peak loads on the system. In other words, the combined increase in electrification and intermittent generation makes the need for flexibility in power systems more of a pressing issue. 
Furthermore, the increasing deployment of decentralised resources able to offer demand-side flexibility is thought provoking due to their incorporation in a cost-effective manner. Most electric devices and processes offer excellent opportunities to provide flexibility to the system. For instance, the storage provided through electric vehicles can help supporting renewable production, by storing the excess of renewable energy to prevent curtailment and discharging it to the grid when additional supply is required. Also, space heating is a relatively slow process in which the thermal buffering of buildings and storage vessels can be used to enable the shifting of energy load over the day. And many other examples could be presented. ${ }^{8}$ However, costeffective ways must be found to manage and harness the flexibility potential offered by decentralized resources. The central question is how to ensure that decentralized resources are used when and where they are most needed, in a way that also meets the grid management needs of system operators [86].

Generally speaking, flexibility is the ability of a resource, whether any component or collection of components of the power system, to respond to the known and unknown changes of power system conditions at various operational timescales [9]. It is an ability. And it is sold in the context of a specific product, rather than as a separate commodity. For instance, flexibility considered in intra-day markets takes the form of energy blocks, and flexibility considered in balancing markets transforms into regulating power [15].

Flexibility has been a central issue in energy markets since their inception. Accordingly, several traditional mechanisms to incentivize flexibility are in place in most existing markets (which operate mainly according to the 'common design framework' described earlier in this chapter). These include efficient centralized scheduling and pricing, day-ahead profit guarantees, make-whole payments, and optimized balancing markets [9].

Also, several energy markets around the world have recently proposed new mechanisms to incentivize increased levels of flexibility to better manage the rising variability and uncertainty of the net load. These include extended marginal pricing based on the convex-hull approach, new design elements for balancing markets (e.g., pay-for-performance regulation), explicit products for flexible ramping provision, and the use of emerging technologies to provide flexibility, such as demand response (DR) and energy storage [9].

At present, however, existing markets have not (yet) converged on specific design elements to incentivize flexibility in system operation. Also, it is important to stress that new design elements such as convex-hull pricing and pay-for-performance ancillary services are in their infancy, and their impact on a changing power system should be analysed further. Simply put, it is currently unclear whether the aforementioned new market design elements provide sufficient incentives to ensure the adequate levels of flexibility.

${ }^{8} \mathrm{An}$ interesting piece of work related to demand response and distributed generation is presented in [87], pointing out the complementary of both approaches. 


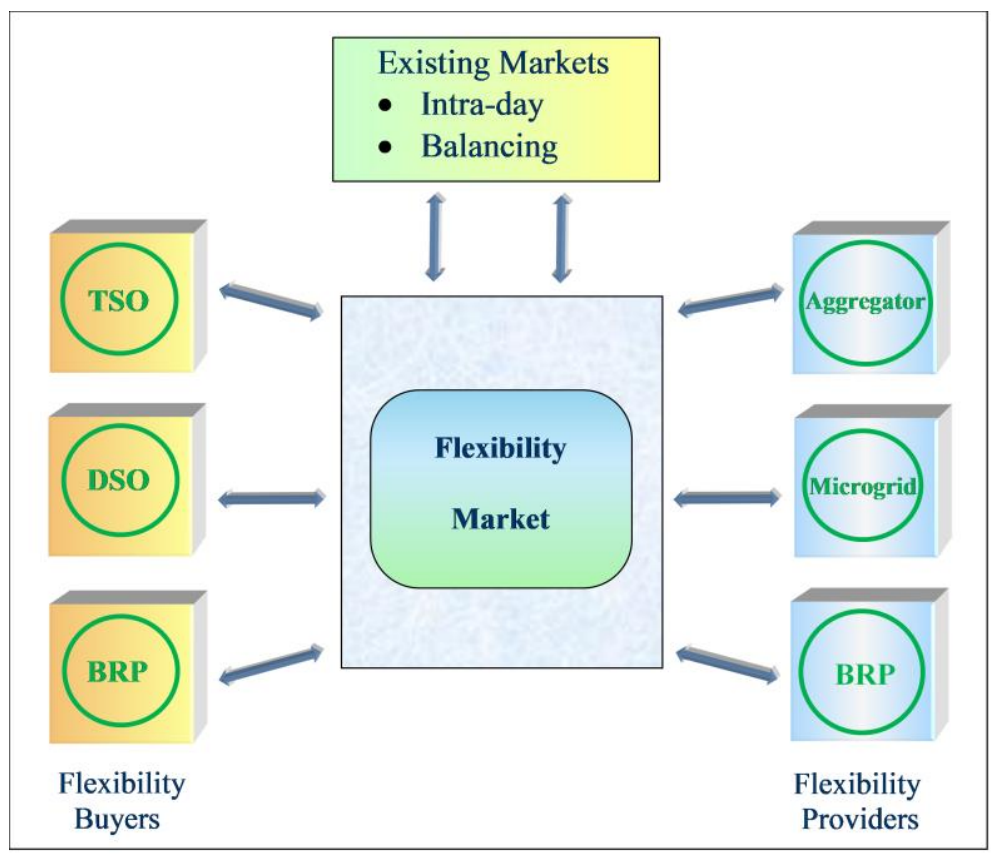

FIGURE 3.3 Generic flexibility market interacting with other existing markets, notably intra-day and balancing markets. The main flexibility buyers include TSOs, DSOs and balancing responsible parties (BRPs), and the key flexibility providers involve micro-grids, aggregators and BRPs.

Flexibility markets refer generally to markets that are used by distributed system operators (DSOs) and possibly also transmission system operators (TSOs) to redispatch their grids, as well as to local markets and per-to-peer trading [88]. Such markets are starting to be recognized as a promising tool to incentivize decentralized resources to trade flexibility products, mitigating the impacts of high levels of renewable generation (see Fig. 3.3). There are a number of ongoing R\&D projects related to flexibility markets (see, e,g, OSMOSE [16] and WindNODE [17]). Several flexibility market platforms are emerging, such as NODES [18], Enera [19], Piclo Flex [20] and GOPACS [21].H. Heer and W. Reek introduce three market platforms (NODES, Enera and GOPACS) in a USEF white paper on flexibility platforms [15]. The authors state that these three pioneering initiatives are essentially in a piloting phase. Also, Schittekatte and Meeus [88] point out that most of the existing literature on flexibility markets focuses on their conceptualization and make a systematic analysis of four market platforms (NODES, Piclo Flex, Enera and GOPACS).

Overall, despite the existence of some exemplary initiatives, most of them use market mechanisms locally and are not connected or integrated into the existing sequence of markets, such as intraday and balancing markets organized by TSOs. 


\subsection{KEY FLEXIBILITY MARKET PLATFORMS}

This section gives an overview of four pioneering flexibility market platforms, namely NODES [18], Enera [19], Piclo Flex [20] and IREMEL [96].

The NODES Marketplace. NODES is an open, integrated market platform for all flexibility providers, balancing responsible parties and grid operators [89]. The platform was established in 2018 as a joint venture between the European power exchange Nord Pool [27] and the Norwegian utility Agder Energi [90]. ${ }^{9}$ The platform is currently installed in several locations, including Germany and Norway [91].

The main objective of NODES is to facilitate the trade of local flexibility by taking into consideration the localisation of the resources. To this end, two key features of the platform are as follows [18]: the possibility to identify local flexibility through a location tag and the capability to give a value to local flexibility by putting a price tag on it. These features open new opportunities to grid operators. In particular, distributed system operators can contract local flexibility to solve grid issues. Also, transmission system operators can access local flexibility that is normally excluded from traditional markets (currently, traditional markets - such as intra-day and balancing markets - are essentially targeting large flexibility sources, meaning that most local flexibility is unable to participate). ${ }^{10}$

Market entities include a market operator, flexibility requesters (or flexibility buyers) and flexibility providers. NODES takes the role of an independent market operator, who provides transparent pricing and secure trading. Transmission system operators, distribution system operators and balancing responsible parties constitute the demand side. ${ }^{11}$ This means that TSOs and DSOs can procure flexibility on the same platform. Flexibility providers include mainly BRPs, although aggregators, retailers, micro-grids and other flexibility owners (e.g., flexible loads) may be considered.

Flexibility buyers may submit offers to the NODES marketplace indicating their willingness to pay for the activation of flexibility at particular locations in the grid. Flexibility providers act on behalf of owners of flexibility assets and may submit bids for sale to NODES. ${ }^{12}$ They need to have a model with asset owners and technology that enables the activation of flexibility by those who buy it in the market. Flexibility assets (e.g., consumers) need to be tagged with their location and can be aggregated by flexibility providers.

\footnotetext{
${ }_{9}^{9}$ Agder Energi is a Norwegian energy group involved in power generation, distribution and trading, as well as in services for customers [86].

10 The interface between NODES and the intra-day market is currently in place. However, the integration of NODES with the balancing market is not yet completed [89].

11 The transmission system operator is not active yet [85]

12 Currently, flexibility trading is based on a continuous procedure [85] and offers are remunerated by considering the pay-as-bid pricing scheme [90].
} 
Flexibility providers can differentiate their bids depending on whether flexibility may be sold locally or centrally [18]. Selling locally, at specific grid locations, may be risky, since flexibility is typically needed locally only a few hundred hours a year. Thus, selling centrally may be advantageous, enabling flexibility to be used for rebalancing contractual positions in the intra-day market (or for balancing purposes by TSOs). Also, flexibility providers can customize their bids by using a wide range of parameters. These include location, availability, time, profile and order parameters. Accordingly, a catalogue of flexibility bids can be built up. Flexibility buyers can filter bids from such a catalogue and choose the ones that best fulfil their needs. For instance, DSOs may be more interested in increased consumption that in curtailment. And TSOs may prefer activation time and ramping. Flexibility products in NODES are, therefore, not standardized. This could be advantageous, allowing to request very specific flexibility needs, and in some cases, to better value flexibility. However, nonstandard flexibility products may not allow for sufficient levels of liquidity, since they increase the difficulty of building up a merit order to organize competition. Non-standard products do not typically promote price transparency nor transparent competition between flexibility providers [88].

Enera and the EPEX SPOT Local Flexibility Market. Enera is part of a funding program of the Federal Ministry for Economic Affairs and Energy, called 'Smart Energy Showcases - Digital Agenda for the Energy Transition' (SINTEG). The program involves 32 consortium partners, including business, research and government. The main goal is to develop and demonstrate scalable standard solutions for an environmentally friendly, secure and affordable power supply (involving large penetrations of renewables). To this end, four different perspectives are being considered: new roles and responsibilities in the energy sector, extension of the regulatory framework, analysis of network charges, and local flexibility markets [19].

In 2018, the European Power Exchange EPEX SPOT and the energy group EWE AG signed a cooperation agreement within the scope of the Enera project. Both companies commit to launch a local market platform for flexibility resources, together with one of the German TSOs (TenneT) and two German DSOs (Avacon Netz and EWE NETZ). The cooperation aims at efficiently tackling the widespread issue of grid congestion by developing a scalable pilot in a showcase region (the windy Northwest of Germany). The solution is expected to be demonstrated in a fully digitalized energy system with $100 \%$ renewables, thus paving the way to the energy market of the future [92].

The EPEX SPOT local market platform is an open and voluntary marketbased congestion management platform for flexibility providers, efficiently centralizing local flexibility offers that can be used by transmission and distribution system operators to alleviate congestion. EPEX SPOT acts as a neutral intermediary between flexibility demand from system operators and flexibility supply from decentralized resources. Also, EPEX SPOT supervises price formation and guarantees a high level of transparency [15]. 
The trading platform operates during the intra-day time frame as a separate platform from the existing sequence of markets [88]. The access to the platform is standardized - that is, market participants can use the same application programming interface which they use to trade in the intraday market. Certified flexibility providers include (or act on behalf) of aggregators, storage assets, and different types of power plants. On a continuous base, they can submit sell offers to their respective order book. Flexibility buyers include TSOs and both mid-voltage and low-voltage DSOs. Also on a continuous base, they can submit demand orders to the order book that corresponds to the market area from which they need flexibility. Order books are, therefore, locational, meaning that a particular market area corresponds to a specific order book on the platform. The trading procedure is similar to the procedure adopted in many intra-day markets across Europe - buy and sell offers in the same order book are automatically and continuously matched. Offers are remunerated by considering the pay-as-bid pricing scheme [93].

Flexibility products are standardized. Product definition is determined by EPEX SPOT in cooperation with grid operators. Most products involve blocks of energy (up or down) for a certain duration and a specific location [88]. Overall, the trading platform aims at creating a powerful coordination between system operators at all grid levels, by relying on a high degree of digitalization and automation. The ambition is to create new opportunities for market participants to value their flexible assets, as well as for system operators to avoid or defer costly grid expansion and allow for a higher reliability, security of supply and coordination [15].

The Piclo Flex Marketplace. Piclo ${ }^{\circledR}$ (the trading name for Open Utility Ltd) is an independent software company that has been active in the energy industry since 2013 [88]. Among other aspects, the company seeks to demonstrate that a marketplace with visibility and transparency at its heart can enable the efficient and fair procurement of flexibility from the rapidly growing number of flexibility providers. Also, it seeks to prove that an open platform could play a fundamental role in supporting the efficient connection and operation of distributed energy resources, therefore supporting the growth of renewable generation and catalyse the adoption of electric vehicles and other initiatives in the clean energy transition [20,94].

Accordingly, Piclo ${ }^{\circledR}$ was involved in a project funded by the UK Government Department of Business, Energy and Industrial Strategy's (BEIS). The project led to the development of the Piclo Flex marketplace, which was piloted in June 2018 for buyers and sellers of flexibility in the UK, and was subsequently launched as a commercial offering from March 2019 [88]. Piclo Flex aims at helping Britain to deliver a smart, flexible and clean energy system, by enabling flexibility providers to promote their services online, as well as by encouraging new initiatives and business models to spring up [20]. 
The piloting phase revealed diversity in the buyers and sellers who can play a role in the flexibility platform. Specifically, the flexibility providers involved essentially aggregators (39.2\% of the total registered providers), electricity suppliers ( $8 \%$ of registrations) and industrial and commercial users $(4.2 \%$ of registrations). However, the trial also revealed some new agents that are poised to join the marketplace, including community and municipality participants (8.5\% of registrations), and some large industrial customers that opted to sign up directly. Also, a relatively large number of participants $(35.4 \%$ of registrations) represented speculative users of the platform, including potential investors in flexibility services [20].

The flexibility buyers included the six DSOs licensed in Britain to distribute electricity in 14 geographically defined areas - that is, UK Power Networks (UKPN), Scottish and Southern Electricity Networks, Electricity North West Limited, Northern Powergrid, SP Networks and Western Power Distribution. Each of the DSOs used the platform in different ways. Some simply considered the visibility features to enhance existing processes, while others considered the functionality to run auctions, publishing their requirements in a standardised format. The type of requirement for flexibility varied but the greatest single need was due to reinforcement deferral. The second-largest requirement was for unplanned interruptions, both pre- and post-fault. Planned maintenance represented a small proportion of flexibility needs during the trial [94].

In 2018-19, during the piloting phase, Piclo Flex signposted demand for more than $456 \mathrm{MW}$ of flexibility from the six DSOs, demonstrating its potential to create a heat-map of areas of network congestion in Britain. UKPN published pricing signals and revenue ranges to accompany their competitions, allocating a total budget of approximately $£ 12$ million. The data revealed the significant variance that may exist between the volume of need and revenue range across the different constraint areas [95].

Overall, Piclo Flex was able to demonstrate that an online platform could be used by DSOs to help manage the electrical grid, using existing distributed assets for reinforcement deferral, unplanned interruptions and planned maintenance. At present, however, the platform seems to be solely used by DSOs, meaning that the cooperation with the TSO is limited. Since establishing a TSO-DSO coordination within a flexibility market takes time, it seems that Piclo Flex decided to move fast by implementing a DSO-only solution. Nevertheless, flexible resources are allowed to engage in revenue stacking (e.g., by also offering services to the TSO) [88].

IREMEL and the Iberian Electricity Market. IREMEL ('Integration of distributed Energy Resources through Local Electricity Markets') is a project launched by OMIE, the Spanish electricity market operator, and IDEA, the Institute for the Diversification and Saving of Energy (Ministry for the Ecological Transition) [96]. 
The main goals of the project are to develop a local market model to facilitate the efficient integration of distributed energy resources (DERs), such as renewables, proactive consumers and storage installations, and also to promote the participation of DERs in solving local congestions and the needs of DSOs. In more detail, the project aims at developing various prototypes of local markets, identifying challenges and opportunities for the pro-active role of prosumers and consumers in these markets (either directly or through the figure of the aggregator), demonstrating the viability of new technologies that facilitate the management of distributed resources and their participation in local markets, and leading the innovation in electricity markets, in cooperation with all stakeholders, and in accordance with the new European regulations (e.g., Directives 2018/2001 [97] and 2019/944 [12]).

IREMEL will involve the most relevant categories of flexibility providers, including large and small DSOs, individual DERs, aggregation companies, proactive consumers, battery producers, etc. All types of providers will participate in the different prototypes in order to validate the correct functioning of the aforementioned local market model [98]. Also, two main sets of products will be considered: short-term products (traded on demand, only when the need arises), and long-term products for structural problems (DSOs rely on the availability of one or more DERs to react in a short term notice, and contract this commitment for a relatively long period, such as months or years).

IREMEL will involve five pilots on local flexibility markets in different Spanish areas, with different participants and under different conditions [98]. However, as far as the author is aware, IREMEL is currently in the design phase.

\subsection{CONCLUSION}

This chapter described the centralized and bilateral models underlying most European markets, and analysed the operation of four central European markets, namely Nord Pool, EPEX Spot, MIBEL and GME. Following this material, the chapter analysed the pressing issue of flexibility in system operation and described three flexibility European market platforms.

The chapter pointed out that the rapid expansion of renewables is challenging power systems in terms of flexibility for short-term operation. It also stated that the increasing deployment of decentralised resources able to offer demandside flexibility is thought provoking due to their incorporation in a cost-effective manner. In this context, the chapter claimed that local flexibility markets are a promising and powerful tool to adequately valorise demand-side flexibility.

The literature on flexibility markets is interesting, although narrow in scope. The SmartEn position paper [98] lists 5 exemplary cases, namely NODES, GOPACS, Enera, IREMEL, and Piclo Flex. Also, H. Heer and W. Reek [15] introduce three pioneering projects to develop flexibility markets: NODES, Enera and GOPACS. The authors point out that these three initiatives are 
conceptually very similar and aim to reach similar benefits for both buyers and sellers of flexibility. The relation to intra-day trading seems to be the main differentiator. Furthermore, the initiatives are essentially in a piloting phase - implementation in operational environments is largely dependent on modifications in regulatory frameworks and organisational changes within system operators.

Schittekatte and Meeus [88] analyse four pioneering initiatives (NODES, Piclo Flex, Enera and GOPACS) in terms of six dimensions: integration with existing markets, role and independence of the market operator, existence of a reservation payment, standardization of flexibility products, TSO-DSO cooperation, and DSO-DSO cooperation. The authors point out that most of the existing literature on flexibility markets focuses on their conceptualization and state that they intend to go a step further. Accordingly, they analyse the four pioneering platforms with the six-dimension framework, and also discuss some design choices that go beyond flexibility market design - that is, choices related to market access, settlement, and responsibilities. They conclude that all platforms are operated by a third party and engage (or tend to engage) with multiple DSOs to become the standardized platform provider. The differences among them are essentially related to their integration into other existing markets, the use of reservation payments, the use of standardized products, and the way TSO-DSO cooperation is done. Also, the authors conclude that the participation in all flexibility markets is voluntary and involves a prequalification procedure. Flexibility providers can either act as BRPs themselves or can trade on behalf of BRPs, meaning that contractual arrangements between (independent) aggregators, suppliers, and BRPs are a topic of debate and dependent on regulatory framework. Finally, the authors state that there is no harmonized approach in calculating the baseline and none of the platforms specify penalties for non-delivery.

As noted earlier, this chapter describes three flexibility European market platforms, specifically NODES, Enera and IREMEL. To some extent, the analysis allow us to conclude that more research is necessary to evaluate the potential impacts of local flexibility markets in a continually changing power system, particularly with respect to their capability to incentivize increased levels of flexibility when such flexibility is needed due to the rising penetrations of renewables. Put simply, sophisticated flexibility markets are not just around the corner, but serious attempts are underway across Europe, indicating that practice is moving faster than conceptual debate. There is, therefore, some further work to be done, but we can expect important technological developments during the coming years towards modern power systems.

\section{ACKNOWLEDGMENT}

This work has received funding from the EU Horizon 2020 research and innovation program under project TradeRES (grant agreement N. 864276). 


\section{Bibliography}

[1] EC, Directive 2003/54/EC of the European Parliament and of the Council, Official Journal of the European Union, (2003) L 176/37-L 176/55

[2] EC, Directive 2009/72/EC of the European Parliament and of the Council, Official Journal of the European Union, (2009) L 211/55-L 211/93

[3] EC, Regulation 1227/2011 of the European Parliament and of the Council, Official Journal of the European Union, (2011) L 326/1-L 326/16

[4] EC, Commission Regulation 2015/1222, Official Journal of the European Union, (2015) L 197/24L $197 / 72$

[5] S. Stoft, Power System Economics: Designing Markets for Electricity. IEEE Press and Wiley Interscience (2002).

[6] D. Kirschen, G. Strbac, Fundamentals of Power System Economics, John Wiley \& Sons, Chichester (2018)

[7] NEMO Committee, EUPHEMIA Public Description: Single Price Coupling Algorithm, Nominated Electricity Market Operators Committee (April 2019)

[8] F. Lopes, H. Coelho, Electricity Markets with Increasing Levels of Renewable Generation: Structure, Operation, Agent-Based Simulation and Emerging Designs, Springer International Publishing, Cham, Switzerland (2018)

[9] E. Ela, M. Milligan, A. Bloom, A. Botterud, A. Townsend, T. Levin, Incentivizing Flexibility in System Operations, In: Electricity Markets with Increasing Levels of Renewable Generation: Structure, Operation, Agent-Based Simulation, and Emerging Designs, Springer International Publishing: Cham, Switzerland (2018), pp. 95-127

[10] E. Ela, M. Milligan, A. Bloom, A. Botterud, A. Townsend, T. Levin, Long-Term Resource Adequacy, Long-Term Flexibility Requirements, and Revenue Sufficiency, In: Electricity Markets with Increasing Levels of Renewable Generation: Structure, Operation, Agent-Based Simulation, and Emerging Designs, Springer International Publishing: Cham, Switzerland (2018), pp. 129-164.

[11] EC, Regulation 2019/943, Official Journal of the European Union, (2019) L 158/54-L 158/124

[12] EC, Directive 2019/944, Official Journal of the European Union, (2019) L 158/125-L 158/199

[13] E. Ela, M. Milligan, A. Bloom, J. Cochran, A. Botterud, A. Townsend, T. Levin, Overview of Wholesale Electricity Markets, In: Electricity Markets with Increasing Levels of Renewable Generation: Structure, Operation, Agent-Based Simulation and Emerging Designs, Springer International Publishing, Cham, Switzerland (2018), pp. 3-21

[14] O. Abrishambaf, P. Faria, Z. Vale, Ramping of Demand Response Event with Deploying Distinct Programs by an Aggregator, Energies 13, 1389 (2020)

[15] H. Heer, W. Reek, USEF White paper: Flexibility platforms, Universal Smart Energy Framework, pp. 1-29 (November 2018). Website: https://www.usef.energy/news-events/publications/ (access date: July 2020)

[16] OSMOSE, Optimal System Mix of Flexibility Solutions for European Electricity, Website: https://www.osmose-h2020.eu/ (access date: July 2020)

[17] WindNODE, Showcasing Smart Energy Systems from North-eastern Germany, Website: https://www.windnode.de/en/about/overview/ (access date: July 2020)

[18] NODES, A Fully Integrated Marketplace for Flexibility: White paper, 2018. Available at: https://nodesmarket.com (access date: July 2020)

[19] Enera, The Next Big Step Towards a Sustainable World, Website: https://bremen-energyresearch.de/projects/enera (access date: July 2020)

[20] Piclo ${ }^{\circledR}$, Flexibility \& Visibility: Investment and Opportunity in a Flexibility Marketplace, Open Utility Ltd (2019) Available at: https://piclo.energy/ (cited on July 2020) 
[21] GOPACS, Grid Operators Platform for Congestion Solutions, Website: https://en.gopacs.eu/ (access date: July 2020)

[22] F. Lopes, Electricity Markets and Intelligent Agents Part I: Market Architecture and Structure. In: Electricity Markets with Increasing Levels of Renewable Generation: Structure, Operation, Agentbased Simulation and Emerging Designs, Springer, Cham (2018), pp. 23-48

[23] F. Schweppe, M. Caramanis, R. Tabors, R., Bohn, Spot Pricing of Electricity, Kluwer Academic Publishers, Boston (1988).

[24] ACER, Methodology for the Price Coupling Algorithm, the Continuous Trading Matching Algorithm and the Intraday Auction Algorithm, Agency for the Cooperation of Energy Regulators Decision on Algorithm Methodology: Annex I (January 2020)

[25] EC, Regulation 2017/1485, Official Journal of the European Union, (2017) L 220/1-L 220/120.

[26] EC, Regulation 2017/2195, Official Journal of the European Union, (2017) L 312/6-L 312/53.

[27] Nord Pool. The Nordic Power Exchange. Website: https://www.nordpoolspot.com/ (access date: July 2020)

[28] Nord Pool, Day-ahead Market Regulations, Nord Pool AS (15 August 2017)

[29] Nord Pool, Intraday Market Regulations, Nord Pool AS (12 June 2018)

[30] Energinet, The Danish Transmission System Operator. Website: https://en.energinet.dk/Electricity (access date: July 2020)

[31] Svenska kraftnät, The Swedish Transmission System Operator. Website: https://www.svk.se/en/stakeholder-portal/Electricity-market/ (access date: July 2020)

[32] Statnett, The Norwegian Transmission System Operator. Website: https://www.statnett.no/en/About-Statnett/ (access date: July 2020)

[33] Entsoe, Nordic Balancing Philosophy, European Network of Transmission System Operators (June 2016)

[34] Energinet, Regulation C2: The Balancing Market and Balance Settlement, The Danish System Operator (December 2017)

[35] Fingrid, Reserve Products and Reserve Marketplaces, Public Presentation of the Finnish System Operator (May 2020).

[36] EPEX SPOT, The European Power Exchange. Website: http://www.epexspot.com/en (access date: July 2020)

[37] EPEX SPOT, Operational Rules, The European Power Exchange (March 2020)

[38] EPEX SPOT, Trading on EPEX SPOT, The European Power Exchange (2020)

[39] RTE, Réseau de Transport d'Électricité, The French Transmission System Operator. Website: https://www.rte-france.com/en (access date: July 2020)

[40] 50Hertz, A Germany Transmission System Operator. Website: https://www.50hertz.com/en/ (access date: July 2020)

[41] Amplion, A Germany Transmission System Operator. Website: https://www.amprion.net/technical-service/ (access date: July 2020)

[42] RTE, Balancing Mechanism, Réseau de Transport d'Électricité (May 2010)

[43] OMIE, The Spanish Electricity Market Operator. Website: https://www.omie.es/en (access date: July 2020)

[44] OMIE, Day-Ahead and Intraday Electricity Market Operating Rules, The Spanish Electricity Market Operator (May 2018)

[45] OMIE, Details of the Intraday Market's Operation, The Spanish Electricity Market Operator (May 2020)

[46] OMIP, Trading Rule Book, The Portuguese Electricity Market Operator (2016)

[47] REN, The Portuguese Transmission System Operator. Website: https://www.ren.pt/en-GB (access date: July 2020)

[48] REE. The Spanish Transmission System Operator. Website: https://www.ree.es/en (access date: July 2020) 
[49] ERSE, Manual de Procedimentos da Gestão Global do Sistema do Setor Elétrico, Entidade Reguladora dos Serviços Energéticos (Junho 2018)

[50] GME. The Italian Electricity Market. Website: http://www.mercatoelettrico.org/En (access date: July 2020)

[51] GME, Vademecum of the Italian Power Exchange, The Italian Electricity Market (2020)

[52] Terna, The Italian Transmission System Operator. Website: https://www.terna.it/en/ (access date: July 2020)

[53] M. Ventosa, A. Baíllo, A. Ramos, M. Rivier, Electricity Market Modelling Trends, Energy Policy 33(7), 897-913 (2005)

[54] E. P. Kahn, Numerical Techniques for Analyzing Market Power in Electricity, Electricity Journal 11(6), 34-43 (1998)

[55] B. F. Hobbs, Linear Complementarity Models of Nash-Cournot Competition in Bilateral and POOLCO Power Markets, IEEE Transactions on Power systems 16(2), 194-202 (2001)

[56] C. J. Day, B. F. Hobbs, Oligopolistic Competition in Power Networks: A Conjectured Supply Function Approach, IEEE Transactions on Power systems 17(3), 597-607 (2002)

[57] A. Weidlich, D. Veit, A Critical Survey of Agent-based Wholesale Electricity Market Models, Energy Economics 30, 1728-1759 (2008)

[58] M. Wooldridge, An Introduction to Multi-agent Systems. John Wiley \& Sons, Chichester (2009)

[59] S. Russell, P. Norvig, Artificial Intelligence: A Modern Approach, Pearson Education, Inc., New Jersey (2020)

[60] S. A. Harp, S. Brignone, B. F. Wollenberg, T. Samad, SEPIA: A Simulator for the Electric Power Industry Agents, IEEE Control Systems Magazine 20(4), 53-69 (2000)

[61] V. Koritarov, Real-World Market Representation with Agents: Modelling the Electricity Market as a Complex Adaptive System with an Agent-Based Approach, IEEE Power \& Energy magazine 2(4), 39-46 (2004)

[62] D. Batten, G. George Grozev, NEMSIM: Finding Ways to Reduce Greenhouse Gas Emissions Using Multi-Agent Electricity Modelling, In: Perez, P. Batten, D. (eds.) Complex Science for a Complex World Exploring Human Ecosystems with Agents, pp. 227-252. Australian National University Press, Canberra (2006)

[63] J. Sun, L. Tesfatsion, Dynamic Testing of Wholesale Power Market Designs: An Open-Source Agent-Based Framework, Computational Economics 30, 291-327 (2007)

[64] F. Sensfuß, Assessment of the Impact of Renewable Electricity Generation on the German Electricity Sector: An Agent-based Simulation Approach, Ph.D. Dissertation, Karlsruhe University (2007)

[65] Z. Vale, T. Pinto, I. Praça H. Morais, MASCEM - Electricity Markets Simulation with Strategically Acting Players, IEEE Intelligent Systems 26(2), 9-17 (2011)

[66] S. Cincotti, G. Gallo, The Genoa Artificial Power-Exchange. In: J. Filipe and A. Fred (eds.), Agents and Artificial Intelligence (ICAART 2012), pp. 348-363. Springer-Verlag, Berlin (2013)

[67] F. Lopes, Electricity Markets and Intelligent Agents: Part II - Agent Architectures and Capabilities. In: Electricity Markets with Increasing Levels of Renewable Generation: Structure, Operation, Agent-Based Simulation and Emerging Designs, Springer: Cham, Switzerland (2018), pp. 49-77

[68] F. Lopes, MATREM: An Agent-based Simulation Tool for Electricity Markets, In: Electricity Markets with Increasing Levels of Renewable Generation: Structure, Operation, Agent-Based Simulation and Emerging Designs, Springer: Cham, Switzerland, pp. 189-225 (2018)

[69] O. Abrishambaf, P. Faria, L. Gomes, J. Spínola, Z. Vale, J. M. Corchado, Implementation of a RealTime Micro-grid Simulation Platform Based on Centralized and Distributed Management, Energies $10,806(2017)$

[70] F. Bellifemine, G. Caire, D. Greenwood, Developing Multi-agent Systems with JADE, John Wiley \& Sons, Chichester (2007) 
[71] D. Vidigal, F. Lopes, A. Pronto, J. Santana, Agent-based Simulation of Wholesale Energy Markets: a Case Study on Renewable Generation. In: Spies, M., Wagner, R., Tjoa, A. (eds.) 26th Database and Expert Systems Applications (DEXA 2015), pp. 81-85. IEEE (2015)

[72] H. Algarvio, A. Couto, F. Lopes, A. Estanqueiro, J. Santana, Multi-agent Energy Markets with High Levels of Renewable Generation: A Case-study on Forecast Uncertainty and Market Closing Time. In: Distributed Computing and Artificial Intelligence, 13th International Conference. AISC, vol. 474, pp. 339-347. Springer, Cham (2016).

[73] H. Algarvio, F. Lopes, A. Couto, A., Estanqueiro, Participation of Wind Power Producers in Dayahead and Balancing Markets: An Overview and a Simulation-based Study, WIREs Energy and Environment 8(5), e343 (2019)

[74] F. Lopes, A. Q. Novais, H. Coelho, Bilateral Negotiation in a Multi-Agent Energy Market, In: Emerging Intelligent Computing Technology and Applications, Springer, Berlin, pp. 655-664 (2009)

[75] F. Sousa, F. Lopes, J. Santana, Contracts for Difference and Risk Management in Multi-agent Energy Markets. In: Advances in Practical Applications of Agents, Multi-Agent Systems, and Sustainability: The PAAMS Collection (PAAMS 2015), Springer International Publishing, pp. 339-347 (2015)

[76] F. Lopes N. Mamede, A. Q. Novais, H. Coelho H, Negotiation in a Multi-agent Supply Chain System. In: Third Int. Workshop of the IFIP WG 5.7 Special Interest Group on Advanced Techniques in Production Planning \& Control, Firenze University Press, pp. 153-168 (2002)

[77] F. Lopes, N. Mamede, A. Q. Novais, H. Coelho, A Negotiation Model for Autonomous Computational Agents: Formal Description and Empirical Evaluation. Journal of Intelligent and Fuzzy Systems, 12, pp. 195-212 (2002)

[78] F. Lopes, N. Mamede, A. Q. Novais, H. Coelho, Negotiation Tactics for Autonomous Agents, In: 12th International Workshop on Database and Expert Systems Applications (DEXA), IEEE, pp. 1$5(2001)$

[79] F. Lopes, J. Sá, J. Santana, Renewable Generation, Support Policies and the Merit Order Effect: A Comprehensive Overview and the Case of Wind Power in Portugal, In: Electricity Markets with Increasing Levels of Renewable Generation: Structure, Operation, Agent-Based Simulation and Emerging Designs, Springer: Cham, Switzerland, pp. 227-263 (2018)

[80] F. Lopes, H. Algarvio, Demand Response in Electricity Markets: An Overview and a Study of the Price-Effect on the Iberian Daily Market, In: Electricity Markets with Increasing Levels of Renewable Generation: Structure, Operation, Agent-Based Simulation and Emerging Designs, Springer: Cham, Switzerland, pp. 265-303 (2018)

[81] H. Algarvio, F. Lopes, A. Couto, A. Estanqueiro, J. Santana, Variable Renewable Energy and Market Design: New Market Products and a Real-world Study, Energies, 12(23), 4576 (2019)

[82] D. Ton, M. Smith, The U.S. Department of Energy's Microgrid Initiative, The Electricity Journal 25, pp. 84-94 (2012)

[83] GridBeyond, Energy Trends in the Global Marketplace, GridBeyond Publication. Website: https://gridbeyond.com/ (access date: July 2020)

[84] USEF, The Framework Explained, Universal Smart Energy Framework, pp. 1-55 (2015). Website: https://www.usef.energy/download-the-framework/a-flexibility-market-design/ (access date: July 2020)

[85] L. Gomes, J. Spínola, Z. Vale, J. M. Corchado, Agent-based architecture for Demand-side Management using Real-time Resources' priorities and a Deterministic Optimization Algorithm, Journal of Cleaner Production 241 (2019)

[86] Europex, A Market-based Approach to Local Flexibility - Design Principles, Position Paper of the Association of European Energy Exchanges (February 2020). Website: https://www.europex.org/publications/ (access date: July 2020) 
[87] Z. Vale, H. Morais, P. Faria, C. Ramos, Distribution System Operation Supported by Contextual Energy Resource Management Based on Intelligent SCADA, Renewable Energy 52, 143-153 (2013)

[88] T. Schittekatte, L. Meeus, Flexibility Markets: Q\&A with Project Pioneers, Utilities Policy 63, 101017 (2020)

[89] NODES, Flexibility Market Platform. Website: https://nodesmarket.com (access date: July 2020)

[90] Agder Energi, Agder Energy Group. Website: https://www.ae.no/en/ (access date: July 2020)

[91] D. Engelbrecht, A. Schweer, R. Gehrcke, E. Lauen, B. Deuchert, J. Wilczek, H. Schuster, J. Büchner, Demonstration of a Market-Based Congestion Management Using a Flexibility Market in Distribution Networks, In: International ETG-Congress, pp. 306-311 (2019)

[92] Press Release, Enera Project: EWE and EPEX SPOT to Create Local Market Platform to Relieve Grid Congestions, Essen, Oldenburg and Paris (06 February 2018). Website: https://www.ewe.com/en/media/press-releases (access date: July 2020)

[93] J. Radecke, J. Hefele, Joseph, L.Hirth, Markets for Local Flexibility in Distribution Networks, Working Paper of ZBW - Leibniz Information Centre for Economics, Kiel, Hamburg (2019)

[94] Piclo ${ }^{\circledR}$, Energy On Trial: Piloting a Flexibility Marketplace to Upgrade our Energy System, Open Utility Ltd (2019) Available at: https://piclo.energy/ (cited on July 2020)

[95] UKPN, Flexible Zones - Revenue Range per Area, UK Power Networks (2019)

[96] OMIE, Modelo de Funcionamento de los Mercados Locales de Electricidad, Project IREMEL, Spanish Electricity Market Operator (June 2019) Website: https://www.omie.es/en/proyecto-iremel (access date: July 2020)

[97] EC, Directive 2018/2001, Official Journal of the European Union, (2018) L 328/82-L 328/209.

[98] SmartEn, Design Principles for (Local) Markets for Electricity System Services, Smart Energy Position Paper (September 2019). Website: https://smarten.eu/design-principles-for-local-marketsfor-electricity-system-services/ (access date: July 2020) 